\title{
Japanse Indigo: Kimono's en textielkunst 1825-2004
}

Indigoblauw, de koning onder de kleurstoffen, is van een mysterieuze schoonheid. Vooral bekend vanwege de blauwe kleur van spijkerbroeken, kan indigo in vele verrassende kleurnuances voorkomen, van een bleek en vaal blauw tot bijna zwart. Indigoverven kent een eeuwenoude traditie die over de hele wereld voorkomt.

In de Japanse textielhistorie speelt indigo een belangrijke rol. Aizome, het verven met indigo, is vermoedelijk rond de $4 \mathrm{e}$ eeuw vanuit China en Korea naar Japan gebracht. Was de kleur aanvankelijk alleen voorbestemd voor gewaden van de hoogste rangen aan het hof van de keizer en verfden de ververs alleen voor het hof, op het einde van de Heian-periode (794-1185) kwam het indigoverven steeds meer in zwang in Kyoto en in de provincies. $\mathrm{Na}$ de val van het keizerlijke rijk was het de militaire bovenlaag die zich tooide in het diep donkerblauw, een kleur die als zeer elegant werd gezien. De blauwe weefsels werden zeer populair rond het begin van de Edo-periode (1600-1867), voor dagelijkse kleding in zowel de stad als op het platteland. Indigo is een kleurechte verfstof en daardoor geschikt voor het verven van weefsels voor intensief gebruik. De pigmenten van de indigoverf hechten zich namelijk aan de vezel, waardoor deze verstevigd wordt en een weefsel geschikt maakt voor zwaar dagelijks gebruik. In de $19 \mathrm{e}$ eeuw werden de praktische blauwe stoffen vooral geassocieerd met het platteland en omschreven als plattelandstextielen. Deze werden genaaid tot kleding voor boeren en vissers en deden dienst als huishoudtextiel, bijvoorbeeld dekbedhoezen (futonii), deurvoorhangen (noren) of inpakdoeken (furoshiki). Zoals de naam al zegt werden deze stoffen op het platteland geproduceerd, ver weg van de steden, hetgeen niet betekent dat ze niet in de steden werden gedragen. Ook voor kimono's in de stadse dracht was de blauwe kleur zeer geliefd.

Het indigoverven vereist grote expertise en heeft zich door de eeuwen heen tot een onafhankelijk beroep ontwikkeld, voor met name mannelijke vaklieden (afb. 1 en 2). De traditie leeft tot op heden voort. Alhoewel de plantaardige indigo grotendeels vervangen is door synthetische indigo daar waar het de massaproductie betreft, zal ceremoniële kleding, haute couture en textielkunst alleen met natuurlijke indigo geverfd worden. De Japanse overheid erkent de cultuurhistorische waarde van het vakmanschap van het indigoverven en heeft aizome opgenomen als beschermd nationaal cultureel erfgoed, met het benoemen van indigoververs tot Important Intangible Cultural Property.

Japans textiel geniet in het Westen een warme belangstelling vanwege de technieken van weven, verven en versieren, maar vooral ook vanwege de vorm, het design en de esthetische waarde Deze interesse is pok oterug te 2023 08:57:53 AM 
Afbeelding 1 (boven) Het leggen van de reeds geweven banen stof op de besneeuwde rijstvelden van Muikamachi, 2003. De combinatie sneeuw en zon heeft een reinigende werking en intensiveert de kleuren. Foto auteur

\section{Afbeelding 2}

Indigoverver Moriyama verf de katoenen garens in de aardewerken indigopotten in zijn verfplaats in Kurume, Fukuoka-prefectuur, 2001. Foto auteur

\section{Afbeelding 3}

(pagina 29)

Zomerkimono vervaardigd door het echtpaar Toshio en Setsuko Honda, in opdracht van het Wereldmuseum Rotterdam met steun van het Mondriaan. fonds. Muikamachi, Niigata-prefectuur, 2004
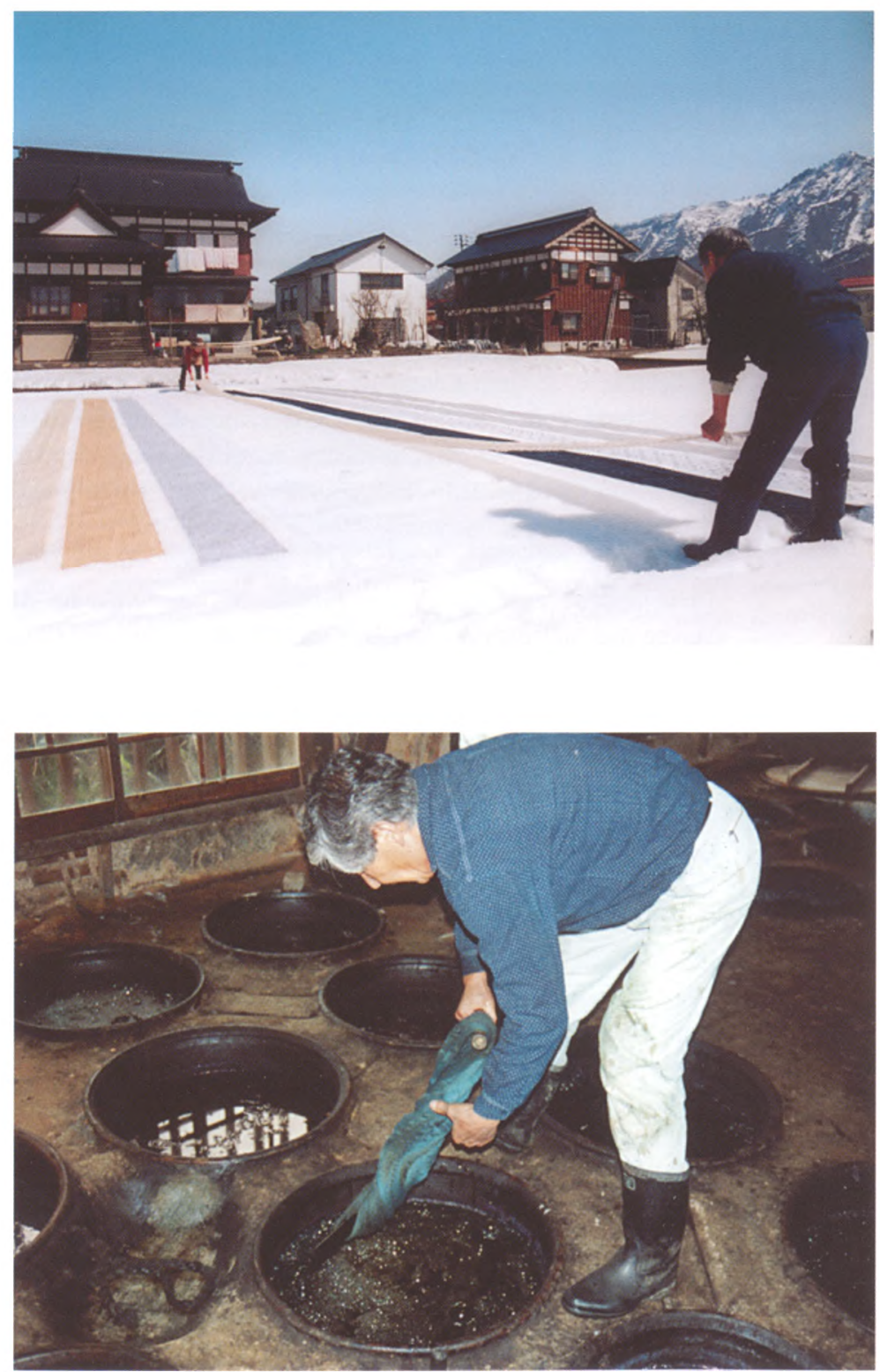

vinden in de diversiteit van de collectie van het Wereldmuseum Rotterdam. Naast de prachtige zijden kimono's heeft het museum een mooie collectie 'plattelandstextielen'. De karakteristieke blauwwitte kleurstelling geeft de stoffen een krachtige uitstraling. Witte geometrische en florale motieven zijn in complexe technieken van verven, bedrukken en borduren aangebracht op een blauwe achtergrond.

In 1955 ondersteunde het museum het onderzoek van de antropoloog Jaap Langewis naar traditionele verf- en weefmethoden in Japan. Hij verzamelde voor het museum meer dan 1000 plattelandstextielen, variërend van kleine fragmenten tot banen stof, kimono's, kleding van brandweerlieden en huishoudelijk textiel. Hij reisde door heel Japan, van Hokkaido in het noorden tot Okinawa in het zuiden. 


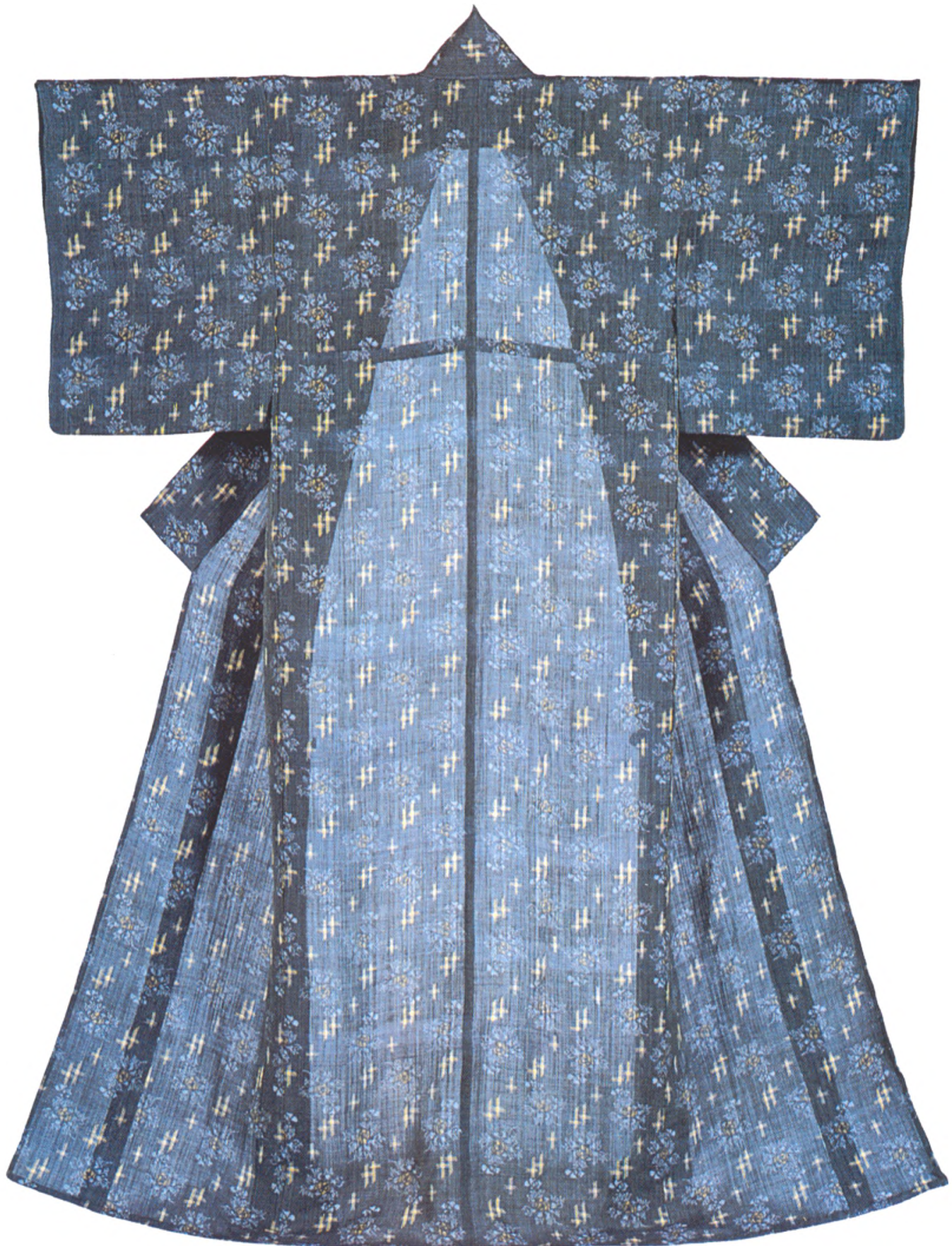


30
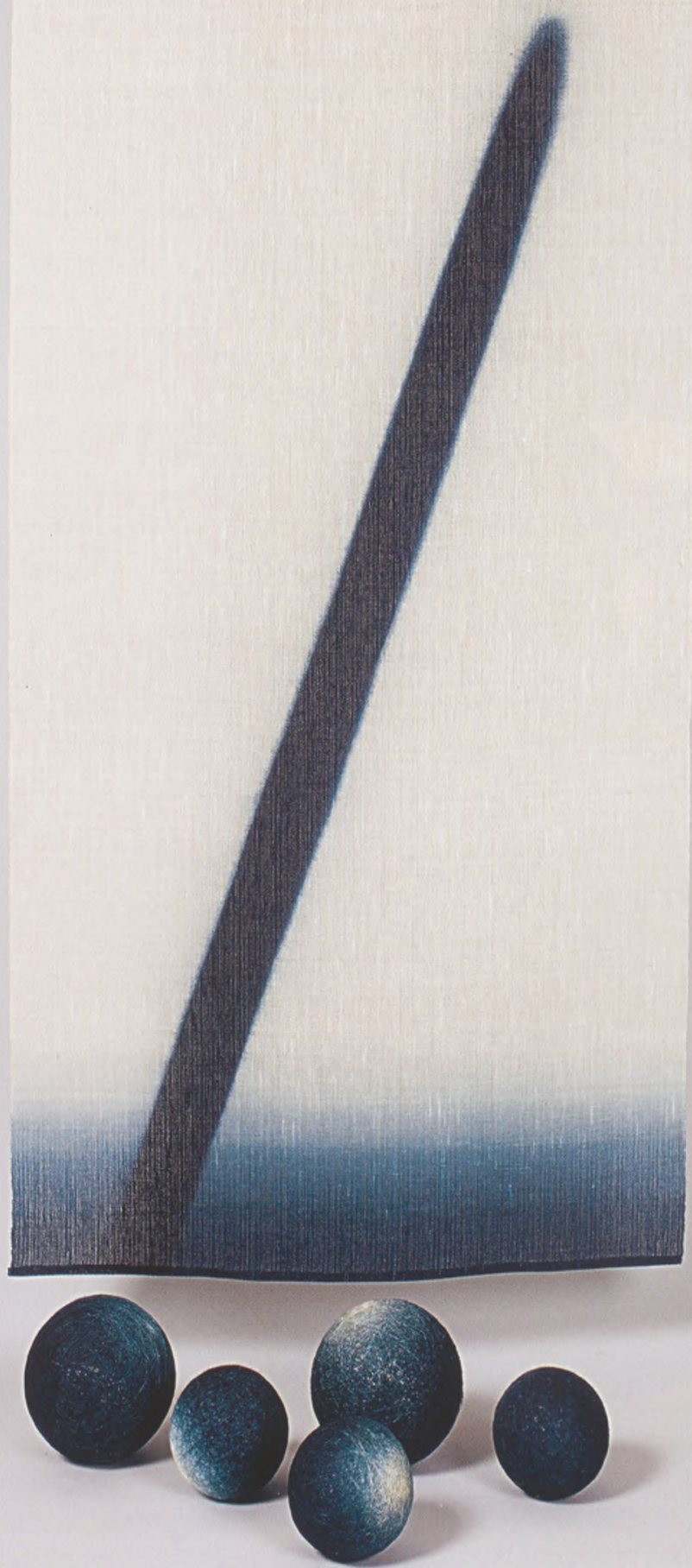

Downloaded from Brill.com04/26/2023 08:57:53AM via free access 
De tentoonstelling laat een selectie van deze stukken zien, aangevuld met nieuwe aanwinsten. Onlangs ontving het museum van een privé-verzamelaar een genereuze gift van kimono's en futondekken. Om de huidige ontwikkeling

\section{Afbeelding 4} (links) Shindo Hiroyuki, Shindigo Balls, 1996; Shindigo Space series, 1997, linnen en indigo. Wereldmuseum Rotterdam, foto Bob Coedewagen van het traditionele indigoverven vast te leggen liet het museum een kimono weven in Niigata prefectuur, in het noorden van Japan (afb. 3). Niigata is bekend vanwege zijn zeer fijne rameeweefsels, de zogenaamde Echigo Jofu, die het keurmerk van Important Intangible Cultural Property dragen. Het weven en het verven van de kimono duurde anderhalf jaar.

Tegelijkertijd wil het museum de plaats van het indigoverven in de hedendaagse Japanse textielkunst tonen. Hiervoor kocht het kunstwerken van Shindo (afb. 4) en Fukumoto, beide uit Kyoto. Alle aankopen zijn ondersteund door de Mondriaan Stichting. Het werk van deze laatste kunstenaar is onderwerp van een aparte opstelling, eveneens in het Wereldmuseum, waarover hieronder meer volgt.

\section{Expressies in Indigo: Textielkunst van Fukumoto Shihoko}

"The nature of indigo synchronizes with my nature. My senses are developed through the process of indigo dyeing. Indigo allows me to interact with nature"

Met deze uitspraak geeft Fukumoto Shihoko heel precies weer hoe zeer zij gefascineerd is door het verven met indigo. Indigoverven is een boeiend spel tussen de verver en de natuur. Een weefsel dat uit het verfbad van de gefermenteerde bladeren van de indigoplant komt, is aanvankelijk groen van kleur. Zodra het met zuurstof in aanraking komt, wordt het blauw. De verver kan kleurgradaties aanbrengen door de inwerking van zuurstof op het verven te manipuleren. Bovendien heeft de verver te maken met de steeds wisselende elementen van de natuur zelf, zoals de temperatuur, de eigenschappen van water en lucht, en de tijd. Het verven met indigo is daardoor nooit hetzelfde en er bestaat dan ook geen vaste formule, omdat de omgevingsfactoren de werking van de indigo altijd bepalen.

Fukumoto Shihoko (Osaka, 1945) ontdekte, na geschoold te zijn in de Westerse schildertechniek aan de Kyoto City University of Arts, in 1976 de schoonheid en het mysterie van het indigoverven. Subtiele tinten blauw in alle gradaties van lichtblauw tot bijna zwart in natuurlijke materialen kenmerken haar schitterende wanddoeken, installaties (een theekamer, afbeelding 5) en stoffen voor kimono's. Shibori, een vorm van het afbinden van de stof middels vouwen, plooien en naaien alvorens te dippen in het indigo verfbad is haar karakteristieke techniek. Vanuit deze traditionele basis creëert ze vernieuwingen met groot respect voor haar materialen: weefsels van katoen uit Turfan, van Japans papier met goudfolie bedekt, van bastvezels zoals hennep, ramee en linnen, van bananenpalm- en van ananasvezel. Om de intens diepblauwe kleuren te krijgen, dipt ze de weefsels wel 30 tot 50 keer in het indigobad. Haar lichtgevende blauwwitte wandkleden hebben zoveel diepte dat zij functioneren als schilderijen.

De basis voor Fukumoto's werk is de overtuiging dat de mysterieuze charme van het indigoverven het best overeenkomt met hetgeen zij wil uitdrukken. Zelf zegt ze over haar werk: "Ik heb altijd het gevoel dat de kleur van de natuurlijke indigo uit Japan is omgeven door spiritualiteit, een speciale zuiverheid en schoonheid. Het verven met indigo verleent mijn werk 'een zeker ruimtebewustzijn', iets dat ik ook in mijzelfmeedraag:"ill.comø4/26/2023 08:57:53AM 
Afbeelding 5

Fukumoto Shihoko,

Tearoom of Morning Mist, 2001, linnen,

Japans papier,

aluminium frame met

lakwerk

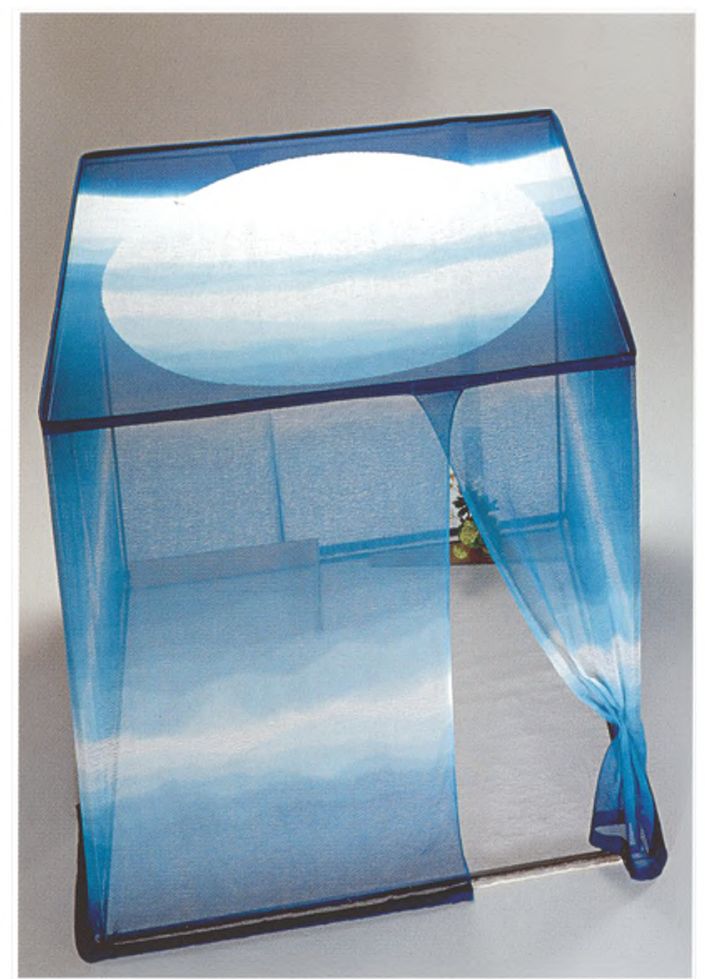

Fukumoto Shihoko is een van Japan's meest vooraanstaande vertegenwoordigers van het indigoverven. Sinds 1979 is haar werk te zien in zowel soloals groepsexposities in Japan, de Verenigde Staten en Europa. Veel van de kunstwerken zijn bekroond met nationale en internationale prijzen en werden opgenomen in de collecties van moderne kunstmusea van Kyoto, Tokyo, New York, Goteborg, evenals in privé-collecties zoals die van Donna Karen. Onlangs verwierf het Wereldmuseum Rotterdam het werk Drifting Light met steun van de Mondriaan Stichting, nu te zien in de expositie 'Japanse Indigo, kimono's en textielkunst $1825-2004$ ' in het Textielkabinet.

Japanse Indigo: kimono's en textielkunst 1825-2004

Textielkabinet Wereldmuseum Rotterdam

Tot 2 oktober 2005

Expressies in indigo, textielkunst van Fukumoto Shihoko Galerie Wereldmuseum Rotterdam

20 maart tot 22 mei 2005

Voor meer informatie: www.wereldmuseum.rotterdam.nl 